\title{
ANALISIS PENGARUH KARAKTERISTIK INDIVIDU TERHADAP MOTIVASI (STUDI PADA PEGAWAI POLITEKNIK ILMU PELAYARAN SEMARANG)
}

\author{
Janny Adriani Djari \\ Dosen Program Studi Nautika PIP Semarang
}

\begin{abstract}
This research aim to to know individual characteristic influence to motivation of Politeknik Ilmu Pelayaran Semarang.

Research regarding do individual characteristic influence intervening motivation and work characteristic to labour capacity take population officer of Politeknik Ilmu Pelayaran Semarang amounting to 218 people. Intake of sample with sampling random technique representing technique intake of sample at random with determination of is amount of sampel used by slovin formula obtained by 142 responder. As for data obtained with kuesioner with data analysis use linear regression.

Pursuant to research which have been done by hence can be obtained by the following conclusion is existence of positive influence and signifikan between individual characteristic to motivation.
\end{abstract}

\section{Keywords : individual characteristic, motivation}

\section{PENDAHULUAN}

Salah satu faktor yang mempengaruhi peningkatan motivasi pegawai dalam suatu organisasi adalah karakteristik individu pegawai (person characteristic) yang terdiri dari pengetahuan, pengalaman kerja, kemampuan dan keterampilan, sikap dan motivasi.

Motivasi merupakan faktor yang penting untuk meningatkan kinerja pegawai. Untuk itu sumber daya manusia yang siap dan mampu untuk maju bersama organisasi demi mencapai tujuan bersama yang diinginkan, merupakan suatu kebutuhan yang tidak bisa ditawar lagi.

Dengan karakteristik individu yang baik akan dapat meningkatkan motivasi pegawai Penelitian sebelumnya mengenai pengaruh karakteristik individu terhadap motivasi pegawai pernah dilakukan oleh Riefka Ghezanda, Bambang Swasto Sunuharyo dan Heru Susilo (2013), Destia Aktarina (2015) serta Sapto Supriyanto, Djabir Hamzah dan Abdul Rahman Kadir (2013) yang menghasilkan karakteristik individu berpengaruh positif dan signifikan terhadap motivasi kerja pegawai. Berbeda hasil penelitian yang dilakukan oleh Didik Chusnul Yakin, Rudy Handoko dan Edy Sutrisno (2013) yang menghasilkan karakteristik individu tidak berpengaruh signifikan terhadap motivasi kerja.

Kajian penelitian mengenai pengaruh karakteristik individu dan karakteristik pekerjaan terhadap motivasi akan dilakukan pada pegawai Politeknik Ilmu Pelayaran Semarang. Politeknik Ilmu Pelayaran Semarang adalah salah satu Lembaga Pendidikan Maritim negeri dibawah naungan Kementerian Perhubungan dan satu-satunya yang berada di Jawa Tengah, yang berlokasi di Jalan Singosari 2A Semarang dengan tugas pokok membina dan mencetak lulusan perwira-perwira kapal niaga, baik kapal-kapal milik negara maupun kapal-kapal swasta.

Berdasarkan latar belakang tersebut di atas, maka peneliti akan menguji tentang pengaruh karakteristik individu terhadap 
Janny Adriani Djari

motivasi (Studi pada Pegawai Politeknik Ilmu Pelayaran Semarang).

\section{Kerangka Penelitian}

Hal yang penting dalam pengelolaan sumber daya manusia adalah mengenai prestasi kerja pegawai. Prestasi kerja pegawai sebagai hasil kerja secara kualitas dan kuantitas yang dapat dicapai oleh

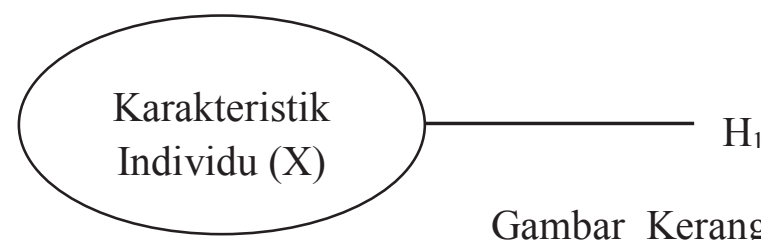

Gambar Kerangka penelitian seseorang pegawai dalam melaksanakan tugas sesuai dengan tanggung jawab yang diberikan kepadanya. Hal yang mendukung motivasi kerja pegawai tersebut adalah karakteristik individu, karakteristik pekerjaan. Berdasarkan uraian tersebut di atas maka dapat disusun kerangka teoritis sebagai berikut :

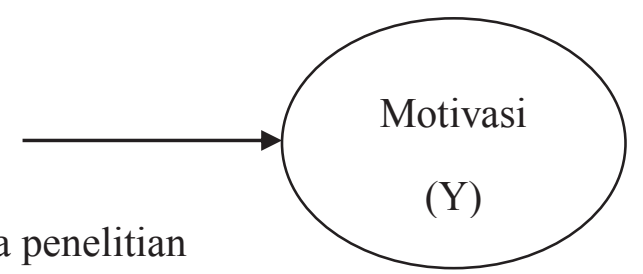

\section{METODE PENELITIAN}

Populasi menurut Sutrisno Hadi (2006) adalah sekumpulan dari seluruh elemenelemen yang dalam hal ini diartikan sebagai objek penelitian. Adapun populasi dalam penelitian ini adalah pegawai Politeknik Ilmu Pelayaran Semarang yang berjumlah 218 orang.

\section{Sampel Penelitian}

Sampel adalah sebagian atau wakil populasi yang akan diteliti (Sutrisno Hadi, 2006).
Sampel dalam penelitian ini adalah pegawai Politeknik Ilmu Pelayaran Semarang. Pengambilan sampel dengan teknik random sampling yang merupakan teknik pengambilan sampel secara acak. Untuk penentuan jumlah sampel berdasarkan pendapat Umar (2009) yang menyatakan jumlah sampel minimal 30 pada kebanyakan penelitian sudah terwakili. Oleh sebab itu penentuan jumlah sampel digunakan rumus slovin dihasilkan 142 responden.

\section{Definisi Konsep, Operasional Dan Pengukuran Variabel}

Tabel Definisi Konsep, Operasional dan Pengukan Variabel

\begin{tabular}{|c|c|c|c|c|}
\hline \multirow[t]{2}{*}{ No } & \multirow[t]{2}{*}{ Variabel } & \multirow[t]{2}{*}{ Definisi Konsep } & \multicolumn{2}{|c|}{ Definisi Operasional } \\
\hline & & & Dimensi & Indikator \\
\hline 1 & $\begin{array}{l}\text { Karakteristik } \\
\text { Individu }\left(\mathrm{X}_{1}\right)\end{array}$ & $\begin{array}{l}\text { Karakteristik individu } \\
\text { yaitu minat, sikap dan } \\
\text { kebutuhan yang dibawa } \\
\text { seseorang ke dalam } \\
\text { situasi kerja (Stoner, } \\
2009 \text { ) }\end{array}$ & $\begin{array}{l}\text { a. Minat } \\
\text { b. Sikap } \\
\text { c. Kebutuhan }\end{array}$ & $\begin{array}{l}\text { 1) Kesesuain dengan pekerjaan } \\
\text { 2) Semangat bekerja } \\
\text { 1) Gaji } \\
\text { 2) Kondisi kerja } \\
\text { 3) Pengawasan } \\
\text { 4) Rekan kerja } \\
\text { 5) Pekerjaan itu sendiri } \\
\text { 6) Kesempatan promosi } \\
\text { 1) Memenuhi kebutuhan } \\
\text { 2) Memotivasi prilaku }\end{array}$ \\
\hline
\end{tabular}




\begin{tabular}{|c|c|c|c|}
\hline Motivasi (Y) & $\begin{array}{lr}\text { Motivasi adalah proses } \\
\text { yang menjelaskan } \\
\text { intensitas, arah dan } \\
\text { ketekunan r seorang } \\
\text { individu r untuk } \\
\text { mencapai } & \text { tujuan } \\
\text { (Robbins, 2006) } & \end{array}$ & $\begin{array}{l}\text { a) Kebutuhan akan } \\
\text { prestasi } \\
\text { b) Kebutuhan akan } \\
\text { kekuasaan } \\
\text { c) Kebutuhan akan } \\
\text { afiliasi }\end{array}$ & $\begin{array}{l}\text { 1) Memiliki kesempatan untuk } \\
\text { berprestasi } \\
\text { 2) Kesempatan untuk } \\
\text { mengikuti pendidikan dan } \\
\text { pelatihan } \\
\text { 3) Bangga hasil kerja menjadi } \\
\text { acuan bagi teman sejawat } \\
\text { 1. Memiliki kewenangan dan } \\
\text { tanggung jawab terhadap } \\
\text { keberhasilan belajar peserta } \\
\text { didik wewenang } \\
\text { 2. Mempunyai sumber } \\
\text { untuk memilih we media } \\
\text { belajar, metode dan media } \\
\text { pembelajaran yang tepat } \\
\text { 3. Mendapatkan kedudukan } \\
\text { yang lebih baik dengan cara } \\
\text { bersaing secara sehat } \\
\text { 1) Menjalin hubungan dengan } \\
\text { peserta didik, teman sejawat, } \\
\text { atasan dan orang tua. } \\
\text { 2) Memiliki kesempatan } \\
\text { membantu teman sejawat } \\
\text { 3) Mendapat penggakuan dari } \\
\text { masyarakat atas profesi } \\
\text { sebagai dosen }\end{array}$ \\
\hline
\end{tabular}

\section{Uji Instrumen Penelitian}

a. Uji Validitas

Uji validitas digunakan untuk mengukur valid tidaknya suatu indikator yang berbentuk kuesioner. Suatu kuesioner dikatakan valid jika pertanyaan mampu untuk mengungkapkan suatu yang akan diukur oleh kuesioner tersebut. Dalam penelitian ini, uji validitas menggunakan analisis faktor yaitu dengan menguji apakah butir-butir indikator atau kuesioner yang digunakan dapat mengkonfirmasikan sebuah faktor atau konstruk. Jika masing-masing pertanyaan merupakan indikator pengukur maka memiliki KMO di atas 0,5 dan signifikansi dibawah 0,05 serta memiliki nilai kriteria loading faktor pengujian sebagai berikut (Ghozali, 2006) :

- Loading faktor > rule of tumb $(0,4)$ berarti valid
- Loading faktor < rule of tumb $(0,4)$ berarti tidak valid

b. Uji Reliabilitas

Suatu alat ukur instrumen disebut reliabel, jika alat tersebut dalam mengukur segala sesuatu pada waktu berlainan, menunjukkan hasil yang relatif sama. Pengukuran reliabilitas dapat dilakukan dengan koefisien Alpha Cronbach menggunakan SPSS For Windows (Ghozali, 2006) dengan kriteria :

- Bila nilai alpha $>0,7$ maka instrumen reliabel

- Bila nilai alpha < 0,7 maka instrumen tidak reliabel

\section{Analisis Regresi Berganda}

Suatu analisa yang digunakan untuk mengetahui persamaan regresi yang menunjukkan persamaan antara variabel 
Janny Adriani Djari

dependent dan variabel independent dengan rumus sebagai berikut :

$\mathrm{Y}=\mathrm{a}+\beta \mathrm{X}$

Keterangan :

$\mathrm{a}=$ Konstanta

$\mathrm{Y}=$ Motivasi

$\mathrm{X}=$ Karakteristik Individu

$\beta=$ Koefisien regresi

$\mathrm{e}=$ Error

\section{Uji Goodness of Fit (Uji Model)}

a. Koefisien determinasi

Koefisien Determinasi (Goodness of fit), yang dinotasikan dengan $\mathrm{R}^{2}$ merupakan suatu ukuran yang penting dalam regresi. Determinasi $\left(\mathrm{R}^{2}\right)$ mencerminkan kemampuan variabel dependen. Tujuan analisis ini adalah untuk menghitung besarnya pengaruh variabel independen terhadap variabel dependen. Nilai $\mathrm{R}^{2}$ menunjukkan seberapa besar proporsi dari total variasi variabel tidak bebas yang dapat dijelaskan oleh variabel penjelasnya. Semakin tinggi nilai $\mathrm{R}^{2}$ maka semakin besar proporsi dari total variasi variabel dependen yang dapat dijelaskan oleh variabel independen (Ghozali, 2006).

b. Uji Signifikan F

Uji signifikan yaitu untuk mengidentifikasi pengaruh variabel independen terhadap variabel dependen dengan menggunakan SPSS (Ghozali, 2006). Adapun kriterianya apabila taraf signifikan $(\alpha)<0,05$.

Pengambilan keputusan :

1) Jika tingkat signifikan $<0,05$, maka seluruh variabel independen berpengaruh signifikan terhadap variabel dependen;

2) Jika tingkat signifikan $>0,05$, maka seluruh variabel independen tidak berpengaruh signifikan terhadap variabel dependen.

\section{Uji Hipotesis}

Uji hipotesis menggunakan uji parsial (uji t) dengan model regresi linier berganda yaitu untuk mengidentifikasi pengaruh variabel independen terhadap variabel dependent secara parsial dengan menggunakan SPSS (Ghozali, 2006). Adapun kriteria hipotesis diterima bila taraf signifikan $\quad(\alpha)<0,05$. Hipotesis yang diajukan sebagai berikut :

Ho : $\beta=0$, Artinya tidak terdapat pengaruh signifikan antara variabel independen terhadap variabel dependen secara parsial.

Ha : $\beta \neq 0$, Artinya terdapat pengaruh signifikan antara variabel independen terhadap variabel dependen secara parsial.

Pengambilan keputusan :

a. Jika tingkat signifikan $<0,05$, maka seluruh variabel independen secara parsial (individual) berpengaruh signifikan terhadap variabel dependen.

b. Jika tingkat signifikan $>0,05$, maka seluruh variabel independen secara parsial (individual) tidak berpengaruh signifikan terhadap variabel dependen.

\section{HASIL PENELITIAN DAN DISKUSI}

\section{Uji Regresi Linier Berganda}

Analisis regresi ganda dengan variabel bebas Pengaruh karakteristik individu dengan variabel terikat adalah motivasi. Dalam analysis ini diperoleh standardized coefisien yang menunjukkan koefisien jalurnya. 
Tabel Hasil Regresi Persamaan

Pengaruh karakteristik individu terhadap motivasi

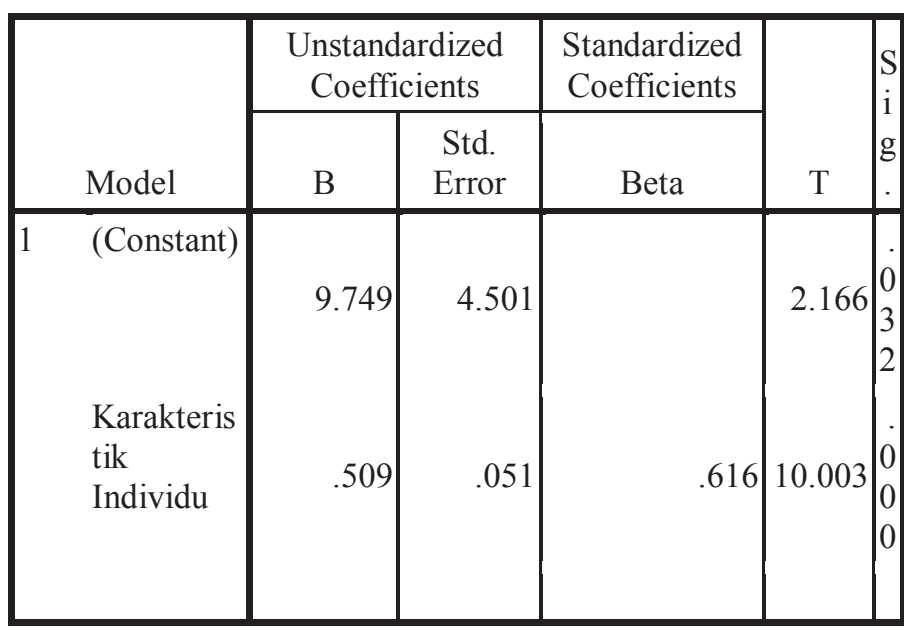

a. Dependent Variable:

Motivasi

Sumber: data primer yang diolah, 2016

Pada tabel di atas hasil analisis regresi persamaan I pengaruh karakteristik individu dan karakteristik pekerjaan terhadap motivasi dapat diketahui persamaan regresi sebagai berikut :

$\mathrm{Y}=0,616 \mathrm{X} 1$

Berdasarkan persamaan tersebut dapat diketahui hasil hipotesis :

Hasil koefisien regresi karakteristik individu 0,616 dan nilai signifikan sebesar $0,000<0,05$. Berdasarkan hasil pengujian dapat disimpulkan bahwa pengujian tersebut mampu menerima $\mathbf{H}$, sehingga dugaan adanya pengaruh antara karakteristik individu terhadap motivasi terbukti atau dapat diterima.

\section{Uji Goodness of Fit (Uji Model)}

\section{- Analisis Koefisien Determinasi}

Analisis koefisien determinasi digunakan untuk mengukur seberapa jauh kemampuan model dalam menerangkan variasi variabel dependen, dimana ditunjukkan dengan nilai $R$ Square. Berikut hasil pengujian yang dibantu dengan program SPSS sebagai berikut :
Tabel Koefisien Determinasi Persamaan

Pengaruh karakteristik individu terhadap motivasi

\begin{tabular}{|l|c|r|r|r|}
\hline \multicolumn{7}{|c|}{ Model Summary } \\
\hline Model & R & R Square & $\begin{array}{c}\text { Adjusted R } \\
\text { Square }\end{array}$ & $\begin{array}{c}\text { Std. Error of } \\
\text { the Estimate }\end{array}$ \\
\hline 1 & $.693^{\mathrm{a}}$ & .480 & .473 & 4.956 \\
\hline
\end{tabular}

a. Predictors: (Constant), Karakteristik Pekerjaan, Karakteristik Individu

\section{Sumber: Data primer yang diolah, 2016}

Berdasarkan tampilan output pada tabel hasil koefisien determinasi persamaan di atas menunjukkan bahwa besarnya prosentase variabel motivasi mampu dijelaskan oleh variabel karakteristik individu dan karakteristik pekerjaan ditunjukkan dengan nilai $R$ Square $\left(\mathrm{R}^{2}\right)$ yaitu sebesar 0,480 Dipilihnya Adjusted $R$ Square agar data tidak bias terhadap jumlah variabel independen yang dimasukkan ke dalam model. Setiap tambahan satu variabel independen, maka $R$ square pasti meningkat tidak perduli apakah variabel tersebut berpengaruh secara signifikan terhadap variabel dependen. Oleh karena itu banyak peneliti untuk menggunakan nilai $R$ Square pada saat mengevaluasi mana model regresi terbaik (Ghozali, 2006). Dalam hal ini dapat diartikan bahwa motivasi mampu dijelaskan oleh variabel karakteristik individu dan karakteristik pekerjaan dengan nilai sebesar $48 \%$, sedangkan sisanya sebesar $52 \%$ dari $(100 \%$ - 48\%) dijelaskan oleh variabel lain yang tidak diteliti dalam penelitian ini.

\section{Uji Model (uji F)}

Uji $\mathrm{F}$ digunakan untuk mengidentifikasi pengaruh variabel independen terhadap variabel dependen secara bersama-sama dan dapat juga untuk menunjukkan kelayakan model persamaan regresi. 
Analisis Pengaruh Karakteristik Individu Terhadap Motivasi (Studi Pada Pegawai Politeknik Ilmu

Pelayaran Semarang)

Janny Adriani Djari

Tabel Hasil Pengujian Model (Uji F) Persamaan Pengaruh karakteristik individu terhadap motivasi

$\operatorname{ANOVA}^{b}$

\begin{tabular}{|l|r|r|r|r|r|}
\hline Model & $\begin{array}{c}\text { Sum of } \\
\text { Squares }\end{array}$ & df & \multicolumn{1}{c|}{$\begin{array}{c}\text { Sean } \\
\text { Square }\end{array}$} & F & Sig. \\
\hline $1 \quad$ Regression & 3156.002 & 2 & 1578.001 & 64.233 & $.000^{\mathrm{a}}$ \\
\multicolumn{1}{|c|}{ Residual } & 3414.794 & 139 & 24.567 & & \\
\multicolumn{1}{|l|}{ Total } & 6570.796 & 141 & & & \\
\hline
\end{tabular}

a. Predictors: (Constant), Karakteristik Pekerjaan,

Karakteristik Individu

b. Dependent Variable:

Motivasi

Sumber : Data primer yang diolah, 2016

Berdasarkan tabel di atas hasil pengujian model (Uji $\mathrm{F})$ pengaruh karakteristik individu dan karakteristik pekerjaan terhadap motivasi dapat diketahui hasil $\mathrm{F}$ hitung 64,233 dan tingkat signifikan $0,000<0,05$ sehingga dapat dikatakan bahwa ada pengaruh antara karakteristik individu terhadap motivasi dan regresi tersebut layak digunakan dalam penelitian.

\section{Pembahasan}

Hasil penelitian yang dilakukan untuk mengetahui pengaruh karakteristik individu terhadap motivasi pada pegawai Politeknik Ilmu Pelayaran Semarang adalah sebagai berikut :

Hasil koefisien regresi karakteristik individu 0,509 dan nilai signifikan sebesar $0,000<0,05$. Berdasarkan hasil pengujian dapat disimpulkan bahwa pengujian tersebut mampu menerima $\mathbf{H}_{1}$, sehingga dugaan adanya pengaruh antara karakteristik individu terhadap prestasi kerja terbukti atau dapat diterima. Hasil penelitian ini sama dengan penelitian yang dilakukan oleh Riefka Ghezanda, Bambang Swasto Sunuharyo dan Heru Susilo (2013), Destia Aktarina (2015) serta Sapto Supriyanto, Djabir Hamzah dan Abdul Rahman Kadir (2013) yang menghasilkan karakteristik individu berpengaruh positif dan signifikan terhadap motivasi kerja pegawai.

Karakteristik individu merupakan perbedaan dari masing-masing pegawai yang dapat mempengaruhi dalam berperilaku dan melakukan suatu pekerjaan (Sedarmayanti, 2009). Dengan mengetahui perbedaan karakter individu, para manajer akan dapat menentukan tugas-tugas yang sesuai dengan karakternya sehingga akan dapat memotivasi kerja pegawai. Semakin karakteristik individu tepat pada pekerjaannya, maka semakin tinggi motivasi kerja pegawai.

\section{SIMPULAN}

Berdasarkan penelitian mengenai pengaruh karakteristik individu terhadap motivasi pada pegawai Politeknik Ilmu Pelayaran Semarang dapat diperoleh kesimpulan sebagai berikut :

Karakteristik individu berpengaruh positif dan segnifikan terhadap motivasi kerja. Dengan demikian semakin tepat karakteristik individu pada pekerjaannya, maka semakin tinggi motivasi kerja pegawai.

\section{DAFTAR PUSTAKA}

Tella, Adeyinka. 2007. Work Motivation, Job Satisfation and Organisational Commmitment of Library Personnel in Academic and Research Libraries in Oyo State, Nigeria, Library Philosopy and Practice 2007

Dessler, Gary. 2000. Manajemen Personalia Teknik dan Konsep Modern. Alih Bahasa : Agus Dharma. Edisi Ketiga. Jakarta : Erlangga

Hasibuan, S.P. Malayu. 2009. Organisasi dan Motivasi. Jakarta: PT. Bumi Aksara 
Henry Simamora. 2004. Sumber Daya Manusia. Yogyakarta : STIE

Ghozali, Imam. 2006. Aplikasi Analisis Multivariate dengan Program SPSS. Semarang : Badan Penerbit Universitas Diponegoro

Mangkunegara, Anwar Prabu. 2009. Perilaku dan Budaya Organisasi, Penerbit Refika Aditama, Bandung.

Maryoto. 2000. Manajemen Sumber Daya Manusia

(Manajemen Kepegawaian). Cetakan ke 8. Bandung : Mandar Maju

Maslow, Abraham H. 1954. Motivation And Personality. New York : Harper \& Row Publiser

Munandar. 2012. Manajemen Sumber Daya Manusia, Jurnal Manajemen Desember 2007

Notoatmojo, K. 2009. Manajemen Sumber Daya Manusia. Jakarta : Bima Aksara

Arifin, Noo. 2012. Analisis Kualitas Kehidupan Kerja, Kinerja, Dan Kepuasan Kerja Pada CV. Duta Senenan Jepara, Jurnal Economia, Volume 8, Nomor 1, April 2012

Robbins, S. P. 2002. Prinsip-Prinsip Perilaku Organisasi (Alih Bahasa oleh Halida dan Dewi Sartika), Edisi Kelima. Jakarta : Erlangga

Suprihantono. 2008. Pengaruh Kompensasi dan Karakteristik Pekerjaan Terhadap Kepuasan Kerja, Wacana, Vol. 4 No. 1 Juli 2000. Surabaya

Hadi, Sutrisno. 2006. Metode Penelitian Riset. Yogyakarta : Yayasan Penerbit Fakultas Biologi UGM 